\title{
Gallon per Day
}

National Cancer Institute

\section{Source}

National Cancer Institute. Gallon per Day. NCI Thesaurus. Code C69100.

A volumetric flow rate defined as the rate at which a certain amount of fluid, expressed in gallons, crosses a given surface or is delivered to a given object or space during the period of time equal to one day. 